\title{
Green markets, eco-certification, and equilibrium fraud
}

\author{
Stephen F. Hamilton ${ }^{\mathrm{a}}$, David Zilberman ${ }^{\mathrm{b}}$ \\ a Department of Economics, The Orfalea College of Business, California Polytechnic State University, San Luis Obispo, CA 93407, USA \\ ${ }^{\mathrm{b}}$ Department of Agricultural and Resource Economics, University of California at Berkeley, Berkeley, CA 94720, USA
}

\begin{abstract}
Consumers voluntarily pay significant price premiums to acquire unobservable environmental attributes in green markets. This paper considers the performance of eco-certification policy under circumstances where consumers cannot discern environmental attributes in goods, but are able to form rational expectations regarding the extent of illicit activities in the green market. The main results are: (i) fraud is less prevalent in green markets when entry barriers limit the number of firms; (ii) conventional environmental policies on polluting techniques increase the incidence of fraud, and can even preclude the use of non-polluting techniques which would otherwise emerge in green markets; (iii) voluntary ecocertification policies can decrease fraud, increase output, and raise profits per firm; and (iv) in cases where the socially optimal resource allocation can be supported, the optimal policy involves negative unit certification fees, positive fixed certification fees and is revenue-generating for the certifying agent.
\end{abstract}

Keywords: Environmental policy; Oligopoly; Monopolistic competition; Vertical differentiation

\section{Introduction}

Markets for environmentally-friendly goods and services are becoming increasingly common. Ecocertification programs now govern the sale of thousands of products in more than 20 countries [18,27] and green products account for approximately $9 \%$ of all new-product introductions in the United States [13]. Consumers pay significant price premiums for organic foods, for "green electricity", for shade-grown and fairtrade coffee, and for various environmental attributes such as sustainable, recycled, non-toxic, biodegradable, and cruelty-free. One reason why consumers buy environmentally-friendly versions of products instead of cheaper, but otherwise equivalent versions is that consuming products that contain environmental attributes is gratifying. Consumers prefer environmental attributes in their products much like they prefer any other desirable product quality attribute in market goods. 
Green markets for environmental attributes are nevertheless different from other markets where product quality attributes are exchanged in two essential ways. First, consumer preferences for environmental attributes often depend on an aspect of production technology, for instance an inverse measure of pollution emissions, and this need not relate to any fungible consumptive qualities of the good. Unlike product quality attributes such as appearance, flavor and durability, which are generally revealed either pre-purchase or postpurchase, environmental attributes may never be perceived at all. This creates an opportunity for fraud in green markets that motivates third-party certification. ${ }^{1}$ Second, the products exchanged in green markets are frequently unbranded, as when fruit and vegetables from different producers are sold under a common organic label. This makes collective reputation issues important in green markets.

This paper examines the performance of eco-certification policy in green markets with the potential for fraud. There are three key elements of the analysis: (i) consumer willingness-to-pay premiums exist for environmentally-friendly products; (ii) certification policy agglomerates firms in quality space under a common eco-label; and (iii) consumers are unable to discern environmental attributes in products, but can nonetheless form rational expectations regarding the overall extent of fraud in the market.

Considerable evidence exists that fraud indeed occurs in green markets. The use of misrepresentative labels has been documented for "GMO-free" foods [3], for "ecofish" and "antibiotic-free" meats [7], and a number of firms have faced criminal prosecution for engaging in fraudulent sales of conventional products as organic (see, e.g., $[8,10,14,23]){ }^{2}$ Information often also exists for consumers to form inferences on the overall quality of environmental attributes traded in green markets. A 1997 study by Consumer Reports detected traces of synthetic pesticides on $25 \%$ of organically-labeled tomatoes, peaches, green bell peppers, and apples [4], and the Seattle Post-Intelligencer recently reported a mix of 4-5\% ordinary fish with environmentally sound seafood under a retailer's "ecofish" label [7].

Our analysis of fraud in green markets is framed by a vertical differentiated market structure in which a conventional good and an eco-friendly good differ according to a single, unobserved production attribute. This structure, which follows Mussa and Rosen [16], has several precursors in the literature on environmental quality provision under oligopoly. Ronnen [20] and Crampes and Hollander [5] consider minimum quality standards with a single low-quality firm and a single high-quality firm. A minimum quality standard, which forces the low-quality firm upwards in quality space, reduces the extent of product differentiation in the market, and this leads to pro-competitive effects. Amacher et al. [1] extend this framework to consider a technology investment stage. As is the case under a minimum quality standard, eco-certification policy generates socially beneficial effects by reducing product differentiation, which occurs when the low-quality firm is more efficient at investing than the high-quality firm. Here, we depart from this structure to consider two vertically differentiated markets - a "brown" market and a "green" market - each of which is comprised of multiple firms. Moreover, because our main focus is on collective reputation and fraud in the green market, we suppress the usual strategic duopoly interaction in vertical differentiation models by considering perfect competition among firms in the brown market.

The model also relates to the literature on common traits (see, e.g., [2,26,15]). In these models, collective reputation develops among members of a group and becomes a public good. Unobserved shocks generate informational externalities among members of the group, but these externalities disappear over time as the common trait is learned. That is, individuals develop reputations. The present paper relates to this literature in the sense that firms sharing a common eco-label develop a collective reputation; however, the element of individual reputation is notably absent. This is because firm-specific information is never revealed to consumers, even through repeated purchase. ${ }^{3}$

\footnotetext{
${ }^{1}$ Eco-certification is an important aspect of green markets, and eco-labels such as the German "Blue Angel", the U.S. "Green Seal" and the Nordic Council "White Swan" encompass broad categories of goods. Other significant eco-certification programs exist for individual products, such as "USDA Certified Organic".

${ }^{2}$ The founder of the nonprofit certification organization Certified Naturally Grown (CNG) states it thus: "a surprising number of USDA certified organic growers use prohibited substances on their own farms in an emergency, (and) other USDA organic growers do everything right on their own farms, but on the way to market stop by and 'top off' the truck with produce from a conventional farm" [24].

${ }^{3}$ This parallels the distinction made in the literature between experience goods and credence goods. For experience goods, revelation of quality attributes occurs through repeated purchase, whereas, for credence goods, both pre-purchase and post-purchase costs of determining whether or not an attribute truly exists are high (see, e.g., $[6,22,19])$.
} 
We study both an oligopoly structure with an exogenous number of firms and a monopolistically competitive equilibrium in the green market. Our results relate to product "purity", which we define as an inverse measure of fraud in the green market. The main findings of the paper can be summarized as follows. First, industrial structure has an important influence on purity in green markets. When the number of firms serving the green market is "small", individual incentives to free-ride on the collective reputation of the ecolabel are tempered, and this facilitates the provision of product purity. As in [12], there is an interesting policy tension between non-compliance (impurity) and market power. Second, eco-certification costs generally have desirable effects on green market performance. Under oligopoly, unit certification costs raise both purity and profits per firm in the green market, and thus provide a motive for voluntary compliance that does not rely on individual reputation. Under monopolistic competition, fixed certification costs serve as a barrier to entry in green markets, but higher fixed costs nevertheless tends to increase output and purity. Third, traditional environmental policies that tax brown techniques and subsidize green ones increase the incidence of fraud. Indeed, the traditional policy approach causes equilibrium fraud to emerge in green markets under circumstances where it otherwise would not. Fourth, an eco-certification policy involving a combination of fixed certification charges and per unit certification fees has the potential to achieve the socially optimal resource allocation. For parameterizations of the model for which this is feasible, the optimal policy involves negative unit certification fees, positive fixed certification fees and is revenue-generating for the certifying agent. Finally, when fraud detection is endogenous, monitoring and enforcement activities can deter illicit activities, but are no more effective in eliminating fraud than eco-certification policies which do not involve any monitoring and enforcement at all.

The paper is organized as follows. Section 2 formulates a model of consumer demand in green markets. Section 3 characterizes the social optimum. Section 4 considers the oligopoly and monopolistically competitive equilibria in the green market under various combinations of environmental regulations and eco-certification policies. Section 5 examines monitoring and enforcement strategies and Section 6 concludes.

\section{The model}

Consider a market with two technologies (polluting and non-polluting) and two goods. The goods are comprised of an identical set of consumptive characteristics, but differ according to a single environmental attribute linked to the technology choice. Throughout, the good produced with the non-polluting technology is denoted $y_{\mathrm{g}}$ and referred to as the green product, and the good produced with the polluting technology is denoted $y_{\mathrm{b}}$ and referred to as the brown product. At equal prices, all consumers prefer green products to brown ones; however, consumers are heterogeneous and vary in their preference for the environmental attribute. $^{4}$

Production technology is unobservable in consumption, and this implies that brown products can work their way into the green market. Let $y_{\mathrm{f}}$ denote the quantity of fraudulently-labeled brown products disguised for sale as green products. There are thus three types of production $\left(y_{\mathrm{b}}, y_{\mathrm{f}}\right.$, and $\left.y_{\mathrm{g}}\right)$ and only two markets. To reconcile production with sales, let $\hat{y}_{\mathrm{b}}$ denote total sales in the brown market and let $\hat{y}_{\mathrm{g}}$ denote total sales in the green market.

The model is framed as follows. Fraud is possible in the green market, because the production technology used to produce the green good is not verified in consumption; however, the extent of fraud is bounded, because consumers are able to form rational expectations about the degree of illicit activities in the market. Consumers can form their beliefs in numerous ways, for instance by exposure to media citing labeling violations, by observing various environmental indicators related to pollution or land use, or by common knowledge of the structure of the game. We assume consumer beliefs, on average, are correct.

Consumer preferences for the green product depend on the objective probability that a randomly chosen sample from the green market results in the selection of a true green good. Throughout, this objective probability is referred to as the purity of the environmental attribute. If all products sold in the green market are in fact fraudulently-labeled brown products, then the environmental attribute has zero purity in the green

\footnotetext{
${ }^{4}$ Green products may be desired for reasons of both personal health and environmental health, and can jointly provide both private and public goods (see [11]).
} 
market, and consumer demand goes to zero. Otherwise, demand in the green market is positive and increasing in purity.

To focus attention on behavior in green markets, we assume the brown good is produced by a competitive industry at a constant unit cost of $c_{\mathrm{b}}$. ${ }^{5}$ Production of the brown good generates pollution, and this creates environmental harm according to the damage function $e=e\left(y_{\mathrm{b}}\right)$, where $e^{\prime}()>$.0 and $e^{\prime \prime}()>$.0 .

Production of the green product does not damage the environment. Green production involves a common component of cost with brown production and an additional cost of creating the environmental attribute. Namely, let $c_{\mathrm{g}}\left(y_{\mathrm{g}}\right)=c_{\mathrm{b}} y_{\mathrm{g}}+c\left(y_{\mathrm{g}}\right)$ denote total cost for producing the green product, where $c($. $)$, the environmental attribute cost function, satisfies $c^{\prime}()>$.0 and $c^{\prime \prime}() \geqslant$.0 . One interpretation of $c($.$) is pollution$ abatement cost. Another interpretation is productivity loss when "brown inputs" are not employed (e.g., the loss of organic crops due to pests).

Firms in the green market can either produce the green product or produce the brown product and disguise it for sale as green. Let $d$ represent unit disguise costs. We confine our attention to circumstances in which crime at least has the potential to pay, and this implies that the production of brown goods disguised as green ones is less costly on the margin than the production of truly green goods; that is, $c^{\prime}\left(y_{\mathrm{g}}\right)>d$ holds in equilibrium.

The green market equilibrium studied below is the non-cooperative Nash equilibrium in true green production, $y_{\mathrm{g}}$, and fraud, $y_{\mathrm{f}}$. We study only symmetric equilibria. Let $n$ denote the number of firms in the green market. The symmetric equilibrium which takes as given the number of firms is called the oligopoly equilibrium, and the specification in which free entry and exit are allowed in the green market is referred to as the monopolistic competition equilibrium.

Suppose for the moment that neither consumers nor the certifying agent engage in monitoring and enforcement activities. In this event, attempts at fraudulent sales always succeed, and it follows that $\hat{y}_{\mathrm{b}}=$ $y_{\mathrm{b}}-y_{\mathrm{f}}$ and $\hat{y}_{\mathrm{g}}=y_{\mathrm{g}}+y_{\mathrm{f}}$. Consequently, purity in the green market is given by

$$
\rho=\frac{y_{\mathrm{g}}}{\hat{y}_{\mathrm{g}}}=\frac{y_{\mathrm{g}}}{y_{\mathrm{g}}+y_{\mathrm{f}}} \text {. }
$$

Consumers choose between three types of goods: an outside good (the numeraire), and two inside goods (the brown good and the green good). Consumers are heterogeneous, and differ according to their demand for product quality. Product quality, $q$, is comprised of a bundle of observable consumptive qualities, $k$, which are held in common by brown and green products, and an additional environmental attribute in the green product, which exists (on average) in the green market with a purity level of $\rho$. For simplicity, these characteristics are assumed to be additively separable, so that $q(k, \rho)=\psi(k)+\rho$. Consumers differ in their preferences for the product according to a taste parameter, $\theta$, which is assumed to be continuously indexed and uniformly distributed over the unit interval. Finally, each consumer has exogenous income of $m$.

Let $p_{\mathrm{b}}$ and $p_{\mathrm{g}}$ denote the market prices of the brown product and the green product, respectively. The indirect utility of a type- $\theta$ consumer who buys good $i$ with quality level $k$ and purity level $\rho$ is given by

$$
V_{i}\left(p_{i}, k, \rho, \theta\right)=m-p_{i}+\theta(\psi(k)+\rho) \text { for } i=b, g,
$$

where $\rho=0$ in the case of the brown good.

Market demands are determined from two critical values of the taste distribution. The preference level of the consumer who is indifferent between purchasing green and brown goods, $\theta_{\mathrm{g}}^{*}=\theta_{\mathrm{g}}^{*}\left(p_{\mathrm{b}}, p_{\mathrm{g}}, \rho\right)$, is found by setting $m-p_{\mathrm{g}}+\theta_{\mathrm{g}}(\psi(k)+\rho)=m-p_{\mathrm{b}}+\theta_{\mathrm{g}} \psi(k)$ and solving for $\theta_{\mathrm{g}}$. Doing so yields $\theta_{\mathrm{g}}^{*}=\left(p_{\mathrm{g}}-p_{\mathrm{b}}\right) / \rho$. All consumers with values of $\theta$ that satisfy $\theta \geqslant \theta_{\mathrm{g}}^{*}$ purchase the green product and the remaining consumers purchase either the brown product or the outside good. The preference level of the consumer who is indifferent between purchasing the brown good and the outside good, $\theta_{\mathrm{b}}^{*}=\theta_{\mathrm{b}}^{*}\left(p_{\mathrm{b}}, k\right)$, is found by setting $m-p_{\mathrm{b}}+$ $\theta_{\mathrm{b}} \psi(k)=m$ and solving for $\theta_{\mathrm{b}}$. This gives $\theta_{\mathrm{b}}^{*}=p_{\mathrm{b}} / \psi(k)$.

\footnotetext{
${ }^{5}$ Fixed costs may also exist to produce brown goods. However, because the goal of the present paper is to examine behavior in the green market, these fixed costs are suppressed. Thus, we implicitly conceive the brown industry to be in a long-run competitive equilibrium with marginal cost and average cost equal to $c_{\mathrm{b}}$ for the representative firm.
} 
Normalizing the number of consumers to one, demand for the brown good and the green good is defined from $\theta_{\mathrm{b}}^{*}$ and $\theta_{\mathrm{g}}^{*}$, respectively, in the case of full market coverage as

$$
\begin{aligned}
& D_{\mathrm{b}}\left(p_{\mathrm{b}}, p_{\mathrm{g}}, \rho\right)=\theta_{\mathrm{g}}^{*}-\theta_{\mathrm{b}}^{*}=\frac{\psi(k) p_{\mathrm{g}}-(\psi(k)+\rho) p_{\mathrm{b}}}{\rho \psi(k)}, \\
& D_{\mathrm{g}}\left(p_{\mathrm{b}}, p_{\mathrm{g}}, \rho\right)=1-\theta_{\mathrm{g}}^{*}=\frac{\rho-p_{\mathrm{g}}+p_{\mathrm{b}}}{\rho} .
\end{aligned}
$$

One possibility in the green market equilibrium is that cost of producing the green attribute is so high that consumers have zero demand for the green attribute, even when it is sold at marginal cost. To ensure that demand for the premium product in Eq. (2) is strictly positive when a product with unit purity $(\rho=1)$ is sold at marginal cost, we assume

$$
1-c^{\prime}\left(y_{\mathrm{g}}^{*}\right)>0
$$

where $y_{\mathrm{g}}^{*}$ is the equilibrium quality produced by the representative firm. For values of marginal attribute cost, $c^{\prime}($.$) , that violate condition (3), a green market does not exist.$

Making use of the definition of sales in each market, $D_{\mathrm{b}}\left(p_{\mathrm{b}}, p_{\mathrm{g}}, \rho\right)=\hat{y}_{\mathrm{b}}$ and $D_{\mathrm{g}}\left(p_{\mathrm{b}}, p_{\mathrm{g}}, \rho\right)=\hat{y}_{\mathrm{g}}$, demand Eqs. (1) and (2) can be inverted to yield

$$
\begin{aligned}
& p_{\mathrm{b}}\left(\hat{y}_{\mathrm{b}}, \hat{y}_{\mathrm{g}}\right)=\psi(k)\left(1-\hat{y}_{\mathrm{b}}-\hat{y}_{\mathrm{g}}\right), \\
& p_{\mathrm{g}}\left(\hat{y}_{\mathrm{b}}, \hat{y}_{\mathrm{g}}, \rho\right)=\psi(k)\left(1-\hat{y}_{\mathrm{b}}-\hat{y}_{\mathrm{g}}\right)+\rho\left(1-\hat{y}_{\mathrm{g}}\right) .
\end{aligned}
$$

Notice that the derived demand for the environmental attribute sold in the green market is proportional to its purity level, $p_{\mathrm{g}}-p_{\mathrm{b}}=\rho\left(1-\hat{y}_{\mathrm{g}}\right)$. That is, if the equilibrium price of the brown good is $\bar{p}_{\mathrm{b}}$, inverse demand for the green good is

$$
p_{\mathrm{g}}\left(\bar{p}_{\mathrm{b}}, \hat{y}_{\mathrm{g}}, \rho\right)=\bar{p}_{\mathrm{b}}+\rho\left(1-\hat{y}_{\mathrm{g}}\right) \text {. }
$$

Demand for the environmental attribute in Eq. (6) depends on total output and purity in the green market. At zero purity, the environmental attribute no longer trades in the green market, and inverse demand for the green good in Eq. (6) becomes horizontal at price $\bar{p}_{\mathrm{b}}$.

\section{The social optimum}

Under oligopoly, the social problem is expressed as the selection of an output-purity triple $\left\{\hat{y}_{\mathrm{b}}, \hat{y}_{\mathrm{g}}, \rho\right\}$ to maximize net consumptive benefits, given the number of firms which operate in the market $(n)$. Under monopolistic competition, the socially optimal resource allocation also considers the efficient distribution of output across firms. The production level of a representative firm in the green market is given by $y_{i, \mathrm{~g}}=\rho \hat{y}_{\mathrm{g}} / n$, and, making use of the identities $y_{\mathrm{f}}=(1-\rho) \hat{y}_{\mathrm{g}}, y_{\mathrm{g}}=\rho \hat{y}_{\mathrm{g}}$ and $y_{\mathrm{b}}=\hat{y}_{\mathrm{b}}+(1-\rho) \hat{y}_{\mathrm{g}}$, the total social cost of production can be written as

$$
C\left(\hat{y}_{\mathrm{b}}, \hat{y}_{\mathrm{g}}, \rho, n\right)=c_{\mathrm{b}} \hat{y}_{\mathrm{b}}+\left[c_{\mathrm{b}}+d(1-\rho)\right] \hat{y}_{\mathrm{g}}+n c\left(\rho \hat{y}_{\mathrm{g}} / n\right)+e\left(\hat{y}_{\mathrm{b}}+(1-\rho) \hat{y}_{\mathrm{g}}\right) .
$$

At the socially optimal levels of production, $y_{\mathrm{b}}^{*}$ and $y_{\mathrm{g}}^{*}$, there are two possibilities regarding the marginal cost of the green attribute: either (i) $c^{\prime}\left(y_{\mathrm{g}}^{*}\right) \leqslant c^{\prime}\left(y_{\mathrm{b}}^{*}\right)$, in which case the socially optimal resource allocation forecloses the brown market; or (ii) $c^{\prime}\left(y_{\mathrm{b}}^{*}\right)<c^{\prime}\left(y_{\mathrm{g}}^{*}\right)$, in which case brown products cost less on the social margin

\footnotetext{
${ }^{6}$ In the case where market coverage is incomplete, the markets for brown and green products would essentially operate as independent markets. With a competitive brown market, the usual differences in strategic effects that emerge under the various circumstances of covered and uncovered markets do not occur here, and the effect of incomplete coverage would influence the outcome in precisely the same way as setting $p_{\mathrm{b}}=0$ in the model.
} 
green products, and the optimal resource allocation potentially involves serving both markets. Attention is confined to the latter case. Specifically, we assume it is cheaper on the margin to produce and disguise brown goods as green ones than it is to produce truly green goods:

$$
c^{\prime}\left(y_{\mathrm{b}}^{*}\right)+d<c^{\prime}\left(y_{\mathrm{g}}^{*}\right)
$$

Aggregate welfare is given by

$$
W=\int_{0}^{\hat{y}_{\mathrm{b}}} p_{\mathrm{b}}\left(x, \hat{y}_{\mathrm{g}}\right) \mathrm{d} x+\int_{0}^{\hat{y}_{\mathrm{g}}} p_{\mathrm{g}}\left(\hat{y}_{\mathrm{b}}, x, \rho\right) \mathrm{d} x-C\left(\hat{y}_{\mathrm{b}}, \hat{y}_{\mathrm{g}}, \rho, n\right),
$$

where total social cost is given by (7).

Under oligopoly, the social optimum satisfies the first-order necessary conditions

$$
\begin{aligned}
& p_{\mathrm{b}}\left(\hat{y}_{\mathrm{b}}, \hat{y}_{\mathrm{g}}\right)=c_{\mathrm{b}}+e^{\prime}\left(y_{\mathrm{b}}\right), \\
& p_{\mathrm{g}}\left(\hat{y}_{\mathrm{b}}, \hat{y}_{\mathrm{g}}, \rho\right)=c_{\mathrm{b}}+\rho c^{\prime}\left(y_{\mathrm{g}} / n\right)+(1-\rho)\left(d+e^{\prime}\left(y_{\mathrm{b}}\right)\right), \\
& \Sigma \equiv \frac{1}{\hat{y}_{\mathrm{g}}} \int_{0}^{\hat{y}_{\mathrm{g}}} \frac{\partial p_{\mathrm{g}}\left(\hat{y}_{\mathrm{b}}, x, \rho\right)}{\partial \rho} \mathrm{d} x-c^{\prime}\left(y_{\mathrm{g}} / n\right)+d+e^{\prime}\left(y_{\mathrm{b}}\right) \geqslant 0 ; \quad(1-\rho) \Sigma=0 .
\end{aligned}
$$

Eqs. (9) and (10) are standard welfare condition that set price equal to marginal social cost in each market. The marginal social cost of producing the green product to a purity standard of $\rho$ is $c_{\mathrm{b}}+\rho c^{\prime}()+.(1-\rho)\left(d+e^{\prime}().\right)$, and this is equated with the green market price in Eq. (10). Expression (11) is the Kuhn-Tucker condition on optimal purity. In markets with an element of impurity $\left(\rho^{*}<1\right)$, it is possible to increase product purity only by replacing brown goods with green goods: The marginal benefit of doing so is

$$
\frac{1}{\hat{y}_{\mathrm{g}}} \int_{0}^{\hat{y}_{\mathrm{g}}}\left(\partial p_{\mathrm{g}}\left(\hat{y}_{\mathrm{b}}, x, \rho\right) / \partial \rho\right) \mathrm{d} x,
$$

and the marginal social cost of doing so is $c^{\prime}()-d-.e^{\prime}(.){ }^{7}$

In the free-entry equilibrium, the social optimum satisfies Eqs. (9)-(11) and

$$
c\left(y_{\mathrm{g}} / n\right)-\rho \hat{y}_{\mathrm{g}} c^{\prime}\left(y_{\mathrm{g}} / n\right) / n=0 .
$$

Eq. (12) ensures the representative firm acquires minimum efficient scale in the market.

Notice that the social optimum involves a trade-off in the allocation of purity. A degree of impurity $\left(\rho^{*}<1\right)$ decreases the surplus acquired by each consumer in the green market in Eq. (11), but reduced purity also lowers cost, driving down the premium price in Eq. (10) and making green products accessible to a greater number of consumers. Because demand in Eq. (6) is linear in purity and the marginal cost of producing green products is separable in the environmental attribute (and bounded by condition (8)), increasing purity always produces a net social benefit. We arrive at (proofs of all propositions are located in the appendix): ${ }^{8}$

Proposition 1. With separable attribute cost and linear demand for purity, the socially optimal resource allocation involves unit purity in the green market, $\rho^{*}=1$.

The socially optimal resource allocation $\left(\rho^{*}=1\right)$ reconciles production and consumption in each market, $\hat{y}_{\mathrm{b}}^{*}=y_{\mathrm{b}}^{*}$ and $\hat{y}_{\mathrm{g}}^{*}=y_{\mathrm{g}}^{*}$, and involves prices set at marginal cost, $p_{\mathrm{b}}^{*}=c_{\mathrm{b}}+e^{\prime}\left(\hat{y}_{\mathrm{b}}^{*}\right)$ and $p_{\mathrm{g}}^{*}=c_{\mathrm{b}}+c^{\prime}\left(\hat{y}_{\mathrm{g}}^{*}\right)$. The premium price in the green market is equal to the increment in marginal social cost, $p_{\mathrm{g}}^{*}-p_{\mathrm{b}}^{*}=c^{\prime}\left(\hat{y}_{\mathrm{g}}^{*}\right)-e^{\prime}\left(\hat{y}_{\mathrm{b}}^{*}\right)>0$, and, in the free-entry case, green production is diversified to minimize industry costs, $n c\left(\hat{y}_{\mathrm{g}}^{*} / n\right) / \hat{y}_{\mathrm{g}}^{*}=c^{\prime}\left(\hat{y}_{\mathrm{g}}^{*} / n\right)$.

\footnotetext{
${ }^{7}$ Disguise costs are necessary in the social optimum to prevent consumers from engaging in the individually optimal behavior of sorting among green products for true green units.

${ }^{8}$ In general, impurity can be optimal in green markets if the distribution of $\theta$ is non-uniform.
} 


\section{Environmental policy and eco-certification}

This section considers the effects of both environmental policy and third party eco-certification on the market equilibrium. In practice, most third party eco-certification policies are combined with some form of monitoring, at least at an auditing level, and penalties are assessed for non-compliance, for instance the removal of fraudulent output from the market. Nonetheless, eco-certification costs alone, absent monitoring and enforcement, have interesting effects on the green market equilibrium. These effects are considered here.

Eco-certification policies may involve both fixed costs and variable costs. For example, unit licensing and inspection fees may be combined with fixed application and auditing costs. ${ }^{9}$ Let $\phi$ denote per unit ecocertification costs and $F$ denote fixed eco-certification costs in the green market. ${ }^{10}$

We also consider the possibility that environmental policy exists to internalize pollution costs in the brown market. To align private and social incentives for brown production (see Eq. (9)), efficient policy would require the equivalent of an environmental tax set at the level of marginal damage, $t=e^{\prime}\left(y_{\mathrm{b}}^{*}\right)$, in the brown market.

Let $\hat{y}_{i \mathrm{~g}}=y_{\text {ig }}+y_{i \mathrm{f}}$ denote the output sold by firm $i$ in the green market, $\hat{y}_{\mathrm{g}}=\sum_{i} \hat{y}_{i \mathrm{~g}}$ denote industry output, and $\rho=\sum_{i} y_{i \mathrm{~g}} / \hat{y}_{\mathrm{g}}$ denote product purity. Firm $i$ 's problem is to select $y_{i \mathrm{~g}}$ and $y_{i \mathrm{f}}$ to maximize profits,

$$
\pi_{i}\left(y_{i \mathrm{~g}}, y_{i \mathrm{f}}, \hat{y}_{\mathrm{g}}, \rho\right)=\left(\bar{p}_{\mathrm{b}}+\rho\left(1-\hat{y}_{\mathrm{g}}\right)-c_{\mathrm{b}}-\phi\right)\left(y_{i \mathrm{~g}}+y_{i \mathrm{f}}\right)-d y_{i \mathrm{f}}-c\left(y_{i \mathrm{~g}}\right)-F .
$$

Denoting the market share of firm $i$ in the green market as $\hat{s}_{i \mathrm{~g}}=\hat{y}_{i \mathrm{~g}} / \hat{y}_{\mathrm{g}}$, the first-order necessary conditions for a maximum can be written

$$
\begin{aligned}
& \Phi_{i \mathrm{f}} \equiv \bar{p}_{\mathrm{b}}+\rho\left(1-\hat{y}_{\mathrm{g}}\right)-\rho \hat{s}_{i \mathrm{~g}}-c_{\mathrm{b}}-\phi-d \leqslant 0, \quad y_{i \mathrm{f}} \Phi_{i \mathrm{f}}=0 ; \\
& \Phi_{i \mathrm{~g}} \equiv \bar{p}_{\mathrm{b}}+\rho\left(1-\hat{y}_{\mathrm{g}}\right)+(1-\rho) \hat{s}_{i \mathrm{~g}}-\hat{s}_{i \mathrm{~g}} \hat{y}_{\mathrm{g}}-c_{\mathrm{b}}-\phi-c^{\prime}\left(\rho \hat{y}_{\mathrm{g}} / n\right) \leqslant 0, \quad y_{i \mathrm{~g}} \Phi_{i \mathrm{~g}}=0 ;
\end{aligned}
$$

where all values are expressed in terms of market share and purity. ${ }^{11}$ Expression (13) gives the optimality condition on fraud. Fraudulent production reduces the premium price in two ways. A marginal increase in fraudulent output increases output in the green market, which reduces the premium price by $-\rho$, and the additional unit of fraud also dilutes market purity, further reducing the premium price by $-\rho\left(1-\hat{y}_{\mathrm{g}}\right) / \hat{y}_{\mathrm{g}}$. In net, a unit of fraud is valued in price as $-\rho / \hat{y}_{\mathrm{g}}$, and this reduces marginal revenue for the representative firm by $-\rho \hat{s}_{i \mathrm{~g}}$. In Eq. (13), the representative firm engages in fraud as long the marginal private benefit of fraudulent production, $\bar{p}_{\mathrm{b}}+\rho\left(1-\hat{y}_{\mathrm{g}}\right)$, exceeds its marginal private cost, $\rho \hat{s}_{i \mathrm{~g}}+c_{\mathrm{b}}+\phi+d$.

Expression (14) gives the necessary condition for production of green goods. An additional green unit increases sales in the green market, which reduces the premium price by $-\rho$, but also increases purity, which raises the premium price by $(1-\rho)\left(1-\hat{y}_{\mathrm{g}}\right) / \hat{y}_{\mathrm{g}}$. The net effect on price of an additional green unit is $(1-\rho) / \hat{y}_{\mathrm{g}}-1$, and this augments firm profits by $\left((1-\rho)-\hat{y}_{\mathrm{g}}\right) \hat{s}_{i \mathrm{~g}}$. The representative firm produces truly green output as long as the marginal private benefit of doing so, $p_{\mathrm{g}}+\left((1-\rho)-\hat{y}_{\mathrm{g}}\right) \hat{s}_{\text {ig }}$, exceeds the marginal private cost, $c_{\mathrm{b}}+\phi+c^{\prime}($.$) .$

If an environmental tax is imposed in the brown industry at the Pigovian level, the competitive equilibrium price of the brown good is $\bar{p}_{\mathrm{b}}=c_{\mathrm{b}}+t$, where $t=e^{\prime}\left(y_{\mathrm{b}}^{*}\right)$. Substituting this into (13) and (14), and evaluating these expressions in the symmetric case, $\hat{s}_{i \mathrm{~g}}=1 / n$, gives

$$
\Phi_{\mathrm{f}}=\rho\left(\frac{n-1}{n}-\hat{y}_{\mathrm{g}}\right)-\tau-d \leqslant 0, \quad y_{\mathrm{f}} \Phi_{\mathrm{f}}=0
$$

\footnotetext{
${ }^{9}$ To meet USDA National Organic Program (NOP) standards, mixed operations producing both organic and non-organic products generally incur inspection and certification costs which vary with output, pay a fixed application fee, and maintain an audit trail by keeping separate accounting records for organic and non-organic operations.

${ }^{10}$ Eco-certification costs have been treated in the literature both as variable costs [9,25] and as fixed costs [1].

${ }^{11}$ It is straightforward to verify that the reaction functions slope downward and demand crosses marginal cost from above in the green market, which is sufficient for existence and stability of the Cournot-Nash equilibrium (see [17]).
} 


$$
\Phi_{\mathrm{g}}=\rho\left(\frac{n-1}{n}-\hat{y}_{\mathrm{g}}\right)+\frac{1-\hat{y}_{\mathrm{g}}}{n}-\tau-c^{\prime}\left(\rho \hat{y}_{\mathrm{g}} / n\right) \leqslant 0, \quad y_{\mathrm{g}} \Phi_{\mathrm{g}}=0
$$

where $\tau=\phi-t$. Notice that an environmental tax on the brown good and a subsidy on the green good $(\phi<0)$ produce isomorphic effects in the green market. This is because, with constant unit costs in the brown industry, the environmental tax is passed through entirely into price, raising the base price for both goods.

The symmetric, monopolistically competitive equilibrium is determined by these two equations, and the free-entry condition which states that profits are zero. This equation, which makes $n$ an endogenous variable, is given by

$$
\hat{y}_{\mathrm{g}}\left(\rho\left(1-\hat{y}_{\mathrm{g}}\right)-d(1-\rho)-\tau\right)=n\left(F+c\left(\rho \hat{y}_{\mathrm{g}} / n\right)\right) .
$$

In both the no-entry and free-entry settings, the symmetric, pure strategy oligopoly equilibrium takes one of three forms. Throughout, we refer to a region I outcome as an equilibrium in which unit purity is provided, a region II outcome as an equilibrium in which impure green products are provided, and a region III outcome as an equilibrium in which zero purity is provided and green market foreclosure occurs.

We address three questions for eco-certification policy: (i) What are the effects on output, prices and purity within each region? (ii) Does eco-certification policy alter the boundaries between regions? And (iii) what are the resulting welfare implications?

Consider first the effect of eco-certification costs and pollution control policy on the boundaries between regions under oligopoly. For a region I outcome with unit purity $\left(\rho^{*}=1\right),\left(\Phi_{\mathrm{f}}<0\right)$ in Eq. (15), and $\Phi_{g}=0$ in Eq. (16). Making use of (16) in (15), a region I outcome occurs when

$$
c^{\prime}(.)<\frac{1+n \tau}{n^{2}}+\left(\frac{n+1}{n}\right) d
$$

For a region II outcome with an element of impurity $\left(0<\rho^{*}<1\right)$ in the market, an interior solution is obtained in Eq. (15) and (16) with $\Phi_{\mathrm{f}}=0$ and $\Phi_{\mathrm{g}}=0$. Solving these equations simultaneously, a region II outcome occurs when

$$
\frac{1+n \tau}{n^{2}}+\left(\frac{n+1}{n}\right) d \leqslant c^{\prime}(.) \leqslant \frac{1}{n}+d .
$$

For a region III outcome, marginal attribute cost is sufficiently high in equilibrium that a positive purity level cannot be supported as a pure strategy Nash equilibrium, $1 / n+d<c^{\prime}($.). A Nash equilibrium does exist in mixed strategies; ${ }^{12}$ however, we do not focus on these outcomes in the present paper and consider only symmetric, pure strategy Nash equilibria.

Under monopolistic competition, the number of active firms, $n^{*}=n\left(c_{\mathrm{b}}, d, \tau, F\right)$, is determined by Eqs. (15) and (16) and free-entry condition (17).

To develop some insight on the three regions of production, consider Fig. 1. Fig. 1 considers the case of green technology with constant unit cost,$c_{d}+\tilde{c}$ where $\tilde{c}$ denotes marginal attribute cost for the green product and depicts outcomes under symmetric oligopoly in $(d, \tilde{c})$-space. The bold $45^{\circ}$ line $(\tilde{c}=d)$ depicts the lower boundary on the cost premium that supports equilibrium fraud. For cost pairs below this line, $\tilde{c}<d$, producing truly green products is less costly than disguising brown goods as green ones, and fraud never emerges. The dashed line at $\tilde{c}=1$ denotes the upper limit on marginal attribute cost given by (3). The upper triangle in the figure thus delineates the cost pairs encompassed by the analysis. The remaining lines divide this area into regions I, II, and III. The bold line at $\tilde{c}^{b}=1 / n+d$ represents the upper boundary on the cost premium that supports a pure strategy Nash equilibrium, and region III is comprised of all cost pairs above this locus. The area beneath the $\tilde{c}^{b}$ locus represents cost pairs that support a green market outcome in pure strategies. In the baseline case with no eco-certification policy $(\tau=0)$, this area is further divided into region I and region II by

\footnotetext{
${ }^{12}$ Assume a pure strategy Nash equilibrium exists which satisfies $\left(\hat{y}_{\mathrm{g}}^{e}, \rho^{e}\right)=(0,0)$. If a firm unilaterally defects by producing green products, $n=1$, it follows by (16) that $\Phi_{\mathrm{g}}<0$ only if $1-c^{\prime}()<$.0 , which contradicts condition (3).
} 


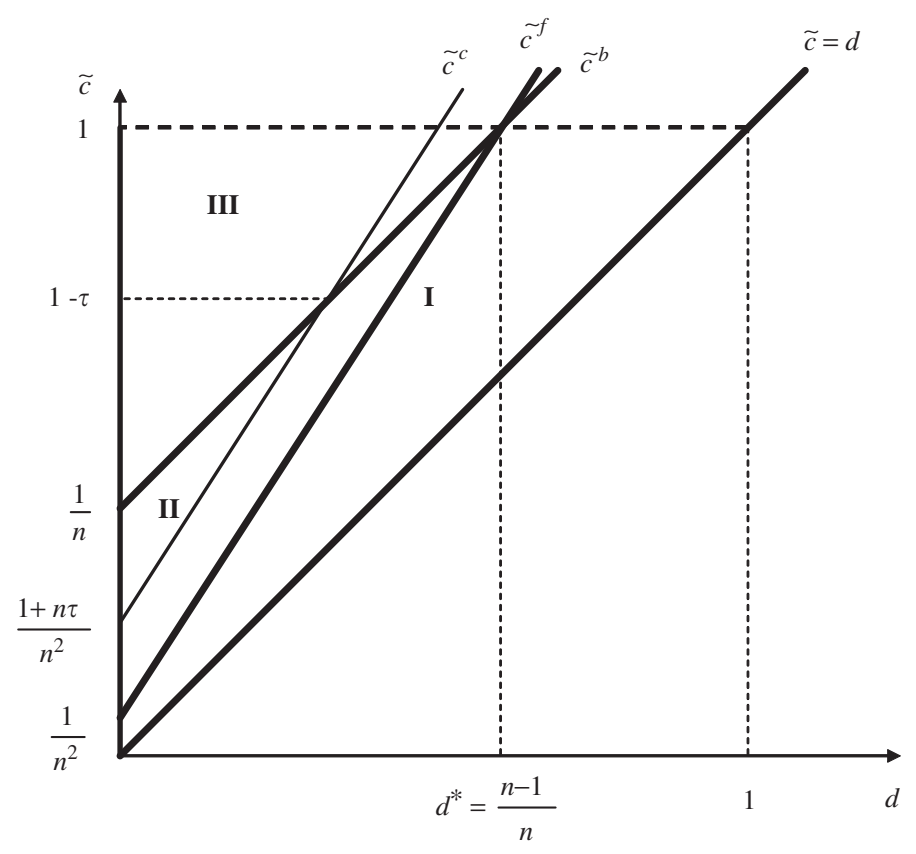

Fig. 1. Equilibrium outcomes under oligopoly.

the locus

$$
\tilde{c}^{\mathrm{f}}=\frac{1}{n^{2}}+\left(\frac{n+1}{n}\right) d
$$

Region I lies below the $\tilde{c}^{\mathrm{f}}$ locus and region II lies between the $\tilde{c}^{\mathrm{b}}$ and $\tilde{c}^{\mathrm{f}}$ loci. From this baseline, the effect of unit eco-certification costs $(\tau>0)$ on the boundaries between regions is to shift upwards the $\tilde{c}^{\mathrm{f}}$ locus to

$$
\tilde{c}^{\mathrm{c}}=\frac{1+n \tau}{n^{2}}+\left(\frac{n+1}{n}\right) d
$$

Positive unit eco-certification costs expand the range of marginal attribute cost that supports unit purity in the oligopoly equilibrium by shifting the $\tilde{c}^{\mathrm{c}}$ locus upward to encompass a larger range of cost pairs. For a representative firm with cost pairs between the $\tilde{c}^{\mathrm{c}}$ the $\tilde{c}^{\mathrm{f}}$ loci in the figure, the imposition of unit ecocertification costs eliminates fraud that would otherwise exist in the market equilibrium. Taxes on dirty techniques $(\tau<0)$ have the opposite effect, shifting the $\tilde{c}^{\mathrm{f}}$ locus downward and reducing the range of industry cost pairs that support a region I outcome.

Under monopolistic competition, the locus

$$
\tilde{c}^{\mathfrak{c}}=\frac{1+n \tau}{n^{2}}+\left(\frac{n+1}{n}\right) d
$$

shifts up and pivots counterclockwise with increases in either $\tau$ or $F$. Eco-certification costs are generally more effective in deterring fraud under monopolistic competition, and this is because of the additional effect of policy on firm exit. The locus $\tilde{c}^{\mathrm{b}}=1 / n+d$ that divides regions II and III shifts linearly upwards with an increase in $F$ due to exit, but shifts downwards with an increase in $\phi$ (because entry occurs in region II following an increase in unit certification costs- see below).

The effect of eco-certification on the boundary regions of the oligopoly and monopolistically competitive equilibria can be summarized as follows: (i) positive unit eco-certification costs can reduce or eliminate fraud in green markets; (ii) environmental taxes on brown techniques can cause fraud to emerge in green markets where it otherwise would not occur; and (iii) fixed eco-certification costs have no effect on behavior under oligopoly, but can reduce or eliminate fraud under monopolistic competition. These results are intuitive. Unit 
eco-certification costs deter fraud by reducing the marginal return to disguising brown goods as green ones, and fixed eco-certification costs mitigate adverse selection in industries with free entry by reducing the number of firms.

The location of the cost loci depends on the industrial structure of the market as follows:

Proposition 2. Without monitoring and enforcement, a green market:

(i) never exists under perfect competition;

(ii) exists with unit purity under monopoly; and

(iii) exists under oligopoly with unit purity when

$$
c^{\prime}\left(\frac{y_{\mathrm{g}}^{*}}{n}\right)<\frac{1+\tau}{n^{2}}+\left(\frac{n+1}{n}\right) d
$$

and with impurity when

$$
\frac{1+\tau}{n^{2}}+\left(\frac{n+1}{n}\right) d \leqslant c^{\prime}\left(y_{\mathrm{g}}^{*} / n\right) \leqslant \frac{1}{n}+d .
$$

Firms face two opposing motivations to engage in green production. The production of true green goods can be profitable, because doing so raises purity and thereby results in an outward shift in market demand. Nevertheless, adverse selection can drive green production away, because it is aggregate, rather than individual, behavior which determines market purity, and the individual firm has no leverage on what others will do. Under competition, the effect of an individual firm's output on purity is negligible, and the first effect disappears. Green market foreclosure occurs. Under monopoly, the effect of purity on sales of market goods is fully internalized, and the second effect disappears. Green markets are unit pure. Under oligopoly, both effects are at work, and the balance between them depends on the number of firms in the industry and on the marginal attribute cost of the representative firm.

The outcome under various green market structures can be seen most clearly in Fig. 1 for the case of no policy $(\tau=0)$. Under monopoly, both the $\tilde{c}^{\mathrm{f}}$ locus and the $\tilde{c}^{\mathrm{b}}$ locus have a unit intercept, and the entire upper triangle becomes region I. With a larger number of firms, both the $\tilde{c}^{\mathrm{f}}$ locus and $\tilde{c}^{\mathrm{b}}$ the locus shift downward, and, in the limit as $n$ tends to infinity, convergence occurs with the $45^{\circ}$ line and the entire upper triangle becomes region III.

Policy also affects behavior within regions. Comparative statics results for the relevant policy variables are presented in Table 1 for regions I and II. ${ }^{13}$ In region I, fraud does not exist in the green market, and policyinduced changes in cost generate the familiar market effects. Under oligopoly, an increase in unit certification costs reduces green output and raises prices, and an increase in fixed certification costs has no effect on output or prices. In the monopolistically competitive equilibrium, higher eco-certification costs reduce green output, raise prices, and induce exit.

In region II, changes in the various model parameters lead to equilibrium adjustments in both output and purity in the green market. Under oligopoly, the equilibrium output level, $\hat{y}_{\mathrm{g}}$, and purity level, $\rho$, are obtained by applying the implicit function theorem jointly on Eqs. (15) and (16). An increase in unit certification costs elevates product purity in the green market, shifting demand to the right and raising the green market price. Consequently, profits rise with higher eco-certification fees. This can make voluntary eco-certification policies possible, even in settings where individual reputation effects are not important.

In the monopolistically competitive equilibrium, the free-entry equilibrium values of $\hat{y}_{\mathrm{g}}, \rho$, and $n$ are defined by Eqs. (15), (16), and entry condition (17). An increase in unit eco-certification costs raises purity and prices, and this stimulates entry. An increase in fixed eco-certification costs induces exit and affects output and purity in the green market according to the sign of the term

$$
\omega=\frac{n-1}{n}-\hat{y}_{\mathrm{g}}\left(1+\rho c^{\prime \prime}(.)\right) \text {. }
$$

\footnotetext{
${ }^{13}$ Calculations of all results are contained in an appendix which is available from the authors upon request.
} 
Table 1

Comparative statics results

\begin{tabular}{|c|c|c|c|c|c|c|}
\hline \multirow[t]{3}{*}{ Exogenous variables } & \multicolumn{6}{|c|}{ Endogenous variables } \\
\hline & \multicolumn{3}{|c|}{ Oligopoly } & \multicolumn{3}{|c|}{ Monopolistic competition } \\
\hline & $\hat{y}_{\mathrm{g}}$ & $\rho$ & $\pi$ & $\hat{y}_{\mathrm{g}}$ & $\rho$ & $n$ \\
\hline \multicolumn{7}{|l|}{ Region I: } \\
\hline$\tau$ & - & 0 & - & - & 0 & - \\
\hline$F$ & 0 & 0 & - & - & 0 & - \\
\hline$n$ & + & 0 & - & & & \\
\hline \multicolumn{7}{|l|}{ Region II: } \\
\hline$\tau$ & - & + & + & - & + & + \\
\hline$F$ & 0 & 0 & - & $?^{\mathrm{a}}$ & $?^{\mathrm{b}}$ & - \\
\hline$N$ & $?^{\mathrm{c}}$ & $?^{\mathrm{d}}$ & - & & & \\
\hline
\end{tabular}

Notes:

${ }^{a}$ sgn $\omega$, where $\omega=$ ( $>0$ for $\rho$ "small")

$$
\omega=\frac{n-1}{n}-\hat{y}_{\mathrm{g}}\left(1+\rho c^{\prime \prime}\right) .
$$

${ }^{\mathrm{b}} \operatorname{sgn} \omega+\frac{2+\rho c^{\prime \prime}}{n}$.

${ }^{\mathrm{c}} \operatorname{sgn}-\omega$
${ }^{\mathrm{d}} \operatorname{sgn}-\left(\omega+\frac{2+\rho c^{\prime \prime}}{n}\right)$.

By inspection of Eq. (15), notice that $\omega>0$ holds for sufficiently small values of $\rho c^{\prime \prime}() \geqslant$.0 , for instance when marginal attribute cost is approximately constant or when the degree of product purity is sufficiently small. When $\omega>0$, higher fixed eco-certification costs raise both output and purity in green markets. Thus, fixed eco-certification costs can serve as an entry barrier and, at the same time, produce pro-competitive effects.

Under oligopoly, the welfare effects of eco-certification can be examined by comparing the outcome that occurs in the market in Eqs. (15) and (16) to the socially optimal resource allocation in Eqs. (9), (10), and (11). This comparison is summarized as follows:

Proposition 3. Under eco-certification, a socially optimal resource allocation:

(i) can always be obtained under monopoly;

(ii) can never be obtained under perfect competition; and

(iii) can be obtained under oligopoly only when

$$
c^{\prime}\left(y_{\mathrm{g}}^{*} / n\right) \leqslant\left(\frac{n}{n-1}\right) d-\frac{e^{\prime}\left(y_{\mathrm{b}}^{*}\right)}{n-1} .
$$

Under oligopoly, it is conceivable to obtain the social optimum with policies that do not rely on monitoring and enforcement. However, because the socially optimal policy requires $\tau<0$ to reconcile private and social output levels (i.e., a subsidy in the green market and a tax in the brown market), this increases the return to fraud and widens the range of cost parameters for which illicit activities occur (see Fig. 1).

Welfare effects in the monopolistically competitive equilibrium can be examined by comparing the outcome that occurs in the market in Eqs. (15), (16), and (17) to the socially optimal resource allocation in Eqs. (9)-(12). 
Proposition 4. A socially optimal resource allocation can be obtained under eco-certification with free-entry only when

$$
c^{\prime}\left(y_{\mathrm{g}}^{*} / n^{*}\right) \leqslant\left(\frac{n^{*}}{n^{*}-1}\right) d-\frac{e^{\prime}\left(y_{\mathrm{b}}^{*}\right)}{n^{*}-1} .
$$

When feasible, the optimal program involves negative unit eco-certification fees, positive fixed certification fees, and generates positive revenue for the certifying agent.

In the monopolistically competitive equilibrium, fixed certification fees can be used to control the number of firms, and this attenuates the common property problem. The social optimum involves a trade-off between diversifying production to achieve the minimum efficient scale of firms and consolidating production to facilitate product purity in the market, and there is no guarantee that unit purity will be provided when the number of firms is selected to minimize industry costs.

The main difficulty with using price instruments to control fraud is that purity decisions hamper policy. It takes a negative eco-certification fee to increase output, whereas a positive eco-certification fee is required to increase purity. This problem can be seen directly by inspection of Eqs. (15) and (16). Notice that the parameter $\tau$ enters additively in both equations, so that it is impossible to discourage fraudulent production without simultaneously discouraging true green production. What is missing is an instrument to uniquely target fraud, for instance a unit tax on disguise. ${ }^{14}$ In the next section, we consider whether monitoring and enforcement activities can fulfill this purpose.

\section{Eco-certification with monitoring and enforcement}

Now consider eco-certification policy which involves independent certification and monitoring of green products. To focus attention on the ability of monitoring to control fraud, suppose inspection does not consume resources. ${ }^{15}$ Let $\alpha \in[0,1]$ denote the monitoring rate selected by the inspecting agent. We assume $\alpha$ is exogenous to firms. Nonetheless, the detection rate for a given $\alpha$ can be endogenous. For example, when firms are organized in mixed operations that produce both brown and green goods and monitoring is done by random sampling, the conditional probability of detection depends on product purity. ${ }^{16}$

Let $\alpha h\left(\rho_{i}\right)$ denote the detection frequency of firm $i$, where $\rho_{i}$ is the purity level of firm $i$ 's green products and $h\left(\rho_{i}\right)$ is the conditional probability of detection given that a monitoring event occurs. Two scenarios are considered: a benchmark case with exogenous detection, $h\left(\rho_{i}\right)=\bar{h}$ for all $\rho_{i}$, and the case of endogenous detection, where $h\left(\rho_{i}\right)$ is assumed to be differentiable with $h(0) 1, h(1)=0, h^{\prime}\left(\rho_{i}\right)<0$, and $h^{\prime \prime}\left(\rho_{i}\right)<0$.

To illustrate the nature of the detection function, $\alpha h\left(\rho_{i}\right)$, and to show our assumptions on it to be reasonably natural, suppose a firm places three types of goods $\left(y_{\mathrm{b}}, y_{\mathrm{g}}\right.$, and $\left.y_{\mathrm{f}}\right)$ into two types of boxes, labeled "brown" and "green". If a monitoring agent inspects green boxes by random sampling, the probability of finding a truly green good in a given box sampled from firm $i$ is $\rho_{i}$. With a sample size of $\mu$ boxes at firm $i$, the detection frequency, $h\left(\rho_{i}\right)=1-\rho_{i}^{\mu}$, satisfies each of the properties above.

Firms face two potential sanctions when fraud is detected: (i) fraudulent output is destroyed; and (ii) a fine of $f \geqslant 0$ is paid on fraudulent units. Positive fines on detected fraud may or may not be used, depending on the authority of the inspecting agent to collect them. ${ }^{17}$

\footnotetext{
${ }^{14}$ It is straightforward to show that increasing disguise costs to $d=1$ would eliminate fraud (see Fig. 1). A subsidy in the green market then could be used to increase true green production to the social optimum.

${ }^{15}$ Extension to the case of costly monitoring effort would be relatively straightforward.

${ }^{16}$ Mixed organizations are not uncommon in green markets. In a recent study of organic producers in Ohio, $42 \%$ of fruit and vegetable producers identified themselves as mixed operations which produce both organic and non-organic, while $50 \%$ identified themselves as producing exclusively organic [21].

${ }^{17}$ In the USDA's NOP standards, monitoring and certification is accomplished by private agents, but fines (currently $\$ 10,000$ per unit) are imposed by USDA for mislabeling products under its organic seal.
} 
Suppose the certifying agent fully inspects all output whenever fraud is detected. A firm producing green goods to a purity standard of $\rho_{i}$ would then expect to make successful sales of

$$
\hat{y}_{i \mathrm{~g}}=y_{i \mathrm{~g}}+\left(1-\alpha h\left(\rho_{i}\right)\right) y_{i \mathrm{f}} \text {. }
$$

The total expected quantity of goods sold in the green market is $\hat{y}_{\mathrm{g}}=\sum_{i} \hat{y}_{i \mathrm{~g}}$.

The removal of detected fraudulent output from the market creates a distinction between the purity of goods produced and the purity of goods sold in the green market. ${ }^{18}$ The purity produced by the representative firm is $\rho=y_{\mathrm{g}} /\left(y_{\mathrm{g}}+y_{\mathrm{f}}\right) a$, and average purity in the market, after screening for fraud, is

$$
\hat{\rho}=\frac{\rho}{1-\alpha h(\rho)(1-\rho)} .
$$

In the analysis to follow, it is helpful to isolate the effect of firm $i$ 's output choice on expected detection, $\beta_{i}\left(\rho_{i}, y_{i \mathrm{f}}\right)=\alpha h\left(\rho_{i}\right) y_{i \mathrm{f}}$. This is done by defining the marginal detection functions,

$$
\begin{aligned}
& \gamma_{i \mathrm{f}}\left(\rho_{i}\right)=\partial \beta_{i}\left(\rho_{i}, y_{i \mathrm{f}}\right) / \partial y_{i \mathrm{f}}=\alpha h\left(\rho_{i}\right)-\rho_{i}\left(1-\rho_{i}\right) \alpha h^{\prime}\left(\rho_{i}\right) \geqslant 0, \\
& \gamma_{i \mathrm{~g}}\left(\rho_{i}\right)=\partial \beta_{i}\left(\rho_{i}, y_{i \mathrm{f}}\right) / \partial y_{i \mathrm{~g}}=\alpha h^{\prime}\left(\rho_{i}\right)\left(1-\rho_{i}\right)^{2} \leqslant 0 .
\end{aligned}
$$

The marginal detection functions have two important properties: The detection rate of firm $i$ is specific to firm $i$; and a marginal increase in either $y_{i f}$ or $y_{i g}$ has no implications for detection when goods are unit pure, $\gamma_{i f}(1)=\gamma_{i c}(1)=0$.

The effect of firm production on market output can be expressed as $\partial \hat{y}_{\mathrm{g}} / \partial y_{i \mathrm{f}}=1-\gamma_{i \mathrm{f}}$ and $\partial \hat{y}_{\mathrm{g}} / \partial y_{i \mathrm{~g}}=$ $1-\gamma_{i g}$. These relationships are intuitive. The effect of an individual firm's production on market sales adjusts each unit increase in output for the change in marginal detection. For an additional unit of fraudulent output, the firm's expected sales of the green good rise by less than one unit, because a higher incidence of fraud increases the detection rate. For an additional unit of true green output, the firm's expected sales of the green good rise by more than one unit, because increased green production serves to launder fraud. Accordingly, the effect of an individual firm's production on market purity is

$$
\frac{\partial \hat{\rho}}{\partial y_{i \mathrm{f}}}=\frac{-\hat{\rho}}{\hat{y}_{\mathrm{g}}}\left(1-\gamma_{i \mathrm{f}}\right) ; \quad \frac{\partial \hat{\rho}}{\partial y_{i \mathrm{~g}}}=\frac{1}{\hat{y}_{\mathrm{g}}}\left(1-\hat{\rho}\left(1-\gamma_{i \mathrm{~g}}\right)\right) .
$$

Under monitoring and enforcement, firm $i$ 's problem is

$$
\operatorname{Max}_{y_{i \mathrm{~g}}, y_{i \mathrm{f}}}\left(\bar{p}_{\mathrm{b}}+\hat{\rho}\left(1-\hat{y}_{\mathrm{g}}\right)-\phi\right) \hat{y}_{i \mathrm{~g}}-\left(c_{\mathrm{b}}+d+\alpha h\left(\rho_{i}\right) f\right) y_{i \mathrm{f}}-c_{\mathrm{b}} y_{i \mathrm{~g}}-c\left(y_{i \mathrm{~g}}\right) .
$$

The first-order necessary conditions in the symmetric case, $\hat{s}_{i \mathrm{~g}}=1 / n, \gamma_{i \mathrm{f}}=\gamma_{\mathrm{f}}$, and $\gamma_{i \mathrm{~g}}=\gamma_{\mathrm{g}}$, are

$$
\begin{aligned}
& \Omega_{\mathrm{f}}=\left(\hat{\rho}\left((n-1) / n-\hat{y}_{\mathrm{g}}\right)-\tau\right)\left(1-\gamma_{\mathrm{f}}\right)-\gamma_{\mathrm{f}}\left(c_{\mathrm{b}}+f\right)-d \leqslant 0 ; \quad y_{\mathrm{f}} \Omega_{\mathrm{f}}=0, \\
& \Omega_{\mathrm{c}}=\left(\hat{\rho}\left((n-1) / n-\hat{y}_{\mathrm{g}}\right)-\tau\right)\left(1-\gamma_{\mathrm{g}}\right)+\left(1-\hat{y}_{\mathrm{g}}\right) / n-\gamma_{\mathrm{g}}\left(c_{\mathrm{b}}+f\right)-c^{\prime}\left(\hat{\rho} \hat{y}_{\mathrm{g}} / n\right) \leqslant 0 ; \quad y_{\mathrm{g}} \Omega_{\mathrm{g}}=0,
\end{aligned}
$$

where use has been made of the regulated brown price, $\bar{p}_{\mathrm{b}}=c_{\mathrm{b}}+t$. Notice that (18) and (19) differ from Eqs. (15) and (16) only by the magnitude of fines, $f$, and by the $\gamma_{\mathrm{f}}$ and $\gamma_{\mathrm{g}}$ terms, which now adjust the equilibrium conditions to account for the effect of each type of production on anticipated market sales, market prices, and penalties. In expression (18), the marginal private benefit of fraud is now lower than in the case without monitoring and enforcement (i.e., $\gamma_{f} \geqslant 0$ ). A marginal unit of fraudulent output now increases the detection rate, which reduces expected marginal revenue (the first term in $\Omega_{\mathrm{f}}$ ). The marginal private cost of fraud is now higher, as well, because a marginal increase in fraudulent output by $\mathrm{d} y_{\mathrm{f}}$ increases the detection rate by $\mathrm{d} \gamma_{\mathrm{f}}$, and this raises the firms anticipated penalty by $\left(c_{\mathrm{b}}+f\right) \mathrm{d} \gamma_{\mathrm{f}}$ (the second term in $\Omega_{\mathrm{f}}$ ). In expression (19), true green production is now more valuable to firms than in the case where monitoring and enforcement do not take place (recall that $\gamma_{\mathrm{g}} \leqslant 0$ ). An additional unit of true green production raises expected green market

\footnotetext{
${ }^{18}$ This raises the interesting possibility that eco-certification activities generate covariance between monitoring effort and prices, which can have additional compliance implications.
} 
sales (the first term in $\Omega_{\mathrm{g}}$ ) and reduces expected penalties (the second term in $\Omega_{\mathrm{g}}$ ). True green production now serves as well to launder fraud.

Notice that the terms $c_{\mathrm{b}}$ and $f$ enter additively in the penalty functions. Detected fraudulent units are destroyed, and this has the same effect on compliance as a fine.

Consider, first, the benchmark case of exogenous detection. In this case, $h\left(\rho_{i}\right)=\bar{h}$ for all $\rho_{i}$, and it follows that $\gamma_{\mathrm{f}}=\alpha \bar{h}$ and $\gamma_{\mathrm{g}}=0$. Eqs. (18) and (19) reduce to

$$
\begin{aligned}
& \Omega_{\mathrm{f}}=\left(\hat{\rho}\left((n-1) / n-\hat{y}_{\mathrm{g}}\right)-\tau\right)(1-\alpha \bar{h})-\alpha \bar{h}\left(c_{\mathrm{b}}+f\right)-d \leqslant 0 ; \quad y_{\mathrm{f}} \Omega_{\mathrm{f}}=0, \\
& \Omega_{\mathrm{g}}=\hat{\rho}\left((n-1) / n-\hat{y}_{\mathrm{g}}\right)+\left(1-\hat{y}_{\mathrm{g}}\right) / n-\tau-c^{\prime}\left(\hat{\rho} \hat{y}_{\mathrm{g}} / n\right) \leqslant 0 ; \quad y_{\mathrm{g}} \Omega_{\mathrm{g}}=0 .
\end{aligned}
$$

Notice that (21) is identical to (16). With exogenous detection, the production of truthful green goods no longer serves to launder fraud. Monitoring and enforcement effort reduces the incentive to produce fraudulent goods in expression (20), but has no direct bearing on the production of green goods. Hence, both $\alpha$ and $f$ uniquely target fraud, and the use of either variable provides the certifying agency with an independent instrument to control it.

Proposition 5. With exogenous detection, a socially optimal resource allocation always can be obtained under eco-certification. Fines are not necessary to support this outcome.

With exogenous detection, the social optimum can be supported under both oligopoly and monopolistic competition. This can be done through the use of a brown tax $(t)$, and various combinations of ecocertification fees $(\phi$ and $F)$ and monitoring effort $(\alpha)$. Moreover, the destruction of detected fraudulent output is sufficient to attain full compliance.

Now consider endogenous detection. From Eqs. (18) and (19), we have

Proposition 6. In an eco-certification program with endogenous detection, a socially optimal resource allocation cannot be obtained under perfect competition and can be obtained under oligopoly only when

$$
c^{\prime}\left(y_{\mathrm{g}}^{*} / n\right) \leqslant\left(\frac{n}{n-1}\right) d-\frac{e^{\prime}\left(y_{\mathrm{b}}^{*}\right)}{n-1} .
$$

As in the case with no monitoring activities at all, eco-certification cannot eliminate equilibrium fraud when detection is endogenous, because the instruments available to the eco-certification agent do not uniquely target fraud. Monitoring and enforcement deters fraud, but full compliance $\left(\rho^{*}=1\right)$ is unattainable for a range of attribute marginal cost. As products become increasingly pure, firms are better able to launder fraud, and the deterrence effect of monitoring becomes negligible. A socially optimal resource allocation is possible under precisely the same conditions that support such an outcome with no monitoring and enforcement at all.

\section{Concluding remarks}

Both the literature on environmental regulation and the emerging literature on eco-certification focus on one of two circumstances: (i) cases where fraud does not exist; and (ii) cases where monitoring and enforcement actions uniquely target illicit behavior. This paper has relaxed these conditions by considering the linkages between policy and equilibrium fraud and between purity and detection. The analysis revealed that environmental policies designed to emphasize green techniques increase the extent of fraud in the economyand may even cause illicit activities to emerge in markets where they otherwise would not. Eco-certification policy, which raises the cost, rather than subsidizes the use of green techniques, reduces equilibrium fraud, and this generally produces desirable welfare effects in green markets. However, the extent to which social welfare can be improved through the use of eco-certification policy depends on the sensitivity of the detection probability to increases in monitoring effort.

The performance of eco-certification policies depends on green market structure. In oligopoly markets where fraud does not occur, for instance due to a high cost of disguising it, unit eco-certification costs reduce output and lower profits per firm; however, when an element of impurity exists in the oligopoly equilibrium, 
positive unit eco-certification costs deter fraud and profits per firm rise in response. Eco-certification fees can thus provide a profit motive for voluntary certification, even in industry settings where reputation effects are unimportant.

The findings in this paper point to an interesting nexus between antitrust regulation, international trade, and eco-certification policy. In markets with unit purity, policies that reduce industry concentration, for instance merger prevention, have desirable pro-competitive effects on output and prices. In markets with a degree of equilibrium fraud, however, policies that reduce industry concentration generally decrease both product purity and output in green markets, producing clear anti-competitive effects. Indeed, it is possible that conventional antitrust policies designed to facilitate market competition lead to green market foreclosure.

In the international trade literature, mandatory national eco-certification schemes are generally viewed as non-tariff trade barriers. ${ }^{19}$ Nevertheless, such policies can also serve a valuable role in facilitating product purity. National requirements that involve fixed eco-certification costs have the potential to increase global output (see Table 1) and can thereby promote, rather than prevent, the international trade of green products.

It should be noted that our results rely on a uniform distribution of consumer preferences for environmental attributes. While a non-uniform distribution of environmental tastes would not alter the main qualitative results of the paper, the shape of the distribution can have important normative implications for policy. To the extent that our analysis has overemphasized the tails of the preference distribution, the socially optimal resource allocation may involve a degree of impurity in green products. Multiple equilibria are also possible where green markets serve those with mild preferences separately from "fanatics".

An interesting possibility for future research is to examine the performance of various eco-certification policies under endogenous detection. The relationship between market purity and the detection rate has particularly interesting implications for the design of efficient monitoring programs in second-best policy settings. Removing detected fraudulent output from a market can generate covariance between monitoring frequency and market price(s), and this creates a link between compliance and the degree of randomization of monitoring effort. It is possible that cost-neutral changes in an inspection profile that increase the variability of the monitoring effort, for instance through less frequent but proportionately more comprehensive inspections, have desirable compliance implications for the control of fraud.

\section{Acknowledgments}

We thank Peter Berck, Philippe Bontems, Robert Innes, Zohra Bouamra Mechemache, Jeff Perloff, David Sunding, participants at the 2005 FSRG conference at the University of Wisconsin, Madison, two anonymous referees, and the editors for helpful comments.

\section{Appendix}

Proof of Proposition 1. Making use of (4) and (5), Eqs. (9)-(11) reduce to

$$
\begin{aligned}
& \psi(k)\left(1-\hat{y}_{\mathrm{b}}-\hat{y}_{\mathrm{g}}\right)=c_{\mathrm{b}}+e^{\prime}, \\
& \psi(k)\left(1-\hat{y}_{\mathrm{b}}-\hat{y}_{\mathrm{g}}\right)+\rho\left(1-\hat{y}_{\mathrm{g}}\right)-c_{\mathrm{b}}-e^{\prime}=\rho\left(c^{\prime}-d-e^{\prime}\right)+d, \\
& 1-\hat{y}_{\mathrm{g}} / 2 \geqslant c^{\prime}-d-e^{\prime} .
\end{aligned}
$$

Next substitute (A.1) into (A.2) and combine this expression with (A.3) to get $\rho \hat{y}_{\mathrm{g}} / 2 \geqslant-d$. This condition must be met with a strict inequality for any positive disguise cost, $0<d$. Hence, the social optimum involves $\rho^{*}=1$.

\footnotetext{
${ }^{19}$ For a thorough examination of the trade effects of eco-labeling restrictions, see [9].
} 
Proof of Proposition 2. For part (i) notice that, when $n \rightarrow \infty, \Phi_{\mathrm{f}}=\rho\left(1-\hat{y}_{\mathrm{g}}\right)-\tau-d$ in Eq. (15) and $\Phi_{\mathrm{g}}=$ $\rho\left(1-\hat{y}_{\mathrm{g}}\right)-\tau-c^{\prime}($.$) in Eq. (16). If true green output is produced, \Phi_{\mathrm{g}}=0$, it follows that $\rho\left(1-\hat{y}_{\mathrm{g}}\right)=c^{\prime}()+.\tau$. Substitution of this into (15) yields $\Phi_{\mathrm{f}}=c^{\prime}()-d \leqslant$.0 for the competitive case, which contradicts. Therefore, true green output is not produced, attribute demand goes to zero, and it follows immediately that $y_{\mathrm{f}}=0$.

For part (ii) notice that $\Phi_{\mathrm{f}}=-\left(\rho \hat{y}_{\mathrm{g}}+\tau+d\right)<0$ when $n=1$. Hence, fraud is never optimal, and the green product has unit purity. It remains only to be shown that the green good is produced in the monopoly equilibrium. At a unit purity level, $\Phi_{\mathrm{g}}=1-2 y_{\mathrm{g}}-\tau-c^{\prime}() \leqslant$.0 and it follows from condition (3) that $y_{\mathrm{g}}^{e}>0$ must hold in the monopoly equilibrium.

Proof of Proposition 3. To obtain the social optimum, the tax must be set at the Pigovian level in the brown market, $t^{*}=e^{\prime}\left(y_{\mathrm{b}}^{*}\right)$, and the value of $\tau$ in Eqs. (15) and (16) must be selected to simultaneously induce unit purity and the social output level that solves (10). Noting that the premium price of the environmental attribute at the optimal resource allocation $\left(\rho^{*}=1\right)$ is defined by $p_{\mathrm{g}}^{*}-p_{\mathrm{b}}^{*}=1-y_{\mathrm{g}}$, the social output level of the green good solves $c^{\prime}\left(y_{\mathrm{g}}^{*} / n\right)-e^{\prime}\left(y_{\mathrm{b}}^{*}\right)=1-y_{\mathrm{g}}^{*}$.

The goal is to reconcile this output level with the region I output level defined by $\Phi_{\mathrm{g}}=0$ in Eq. (16). It follows after some manipulation that $y_{\mathrm{g}}^{e, I}=y_{\mathrm{g}}^{*}$ for

$$
\phi^{*}=-\left(1+e^{\prime}\left(y_{\mathrm{b}}^{*}\right)-c^{\prime}\left(y_{\mathrm{g}}^{*} / n\right)\right) / n .
$$

Substitution of (A.4) and $t=e^{\prime}\left(y_{\mathrm{b}}^{*}\right)$ into (15), unit purity is an equilibrium outcome when

$$
c^{\prime}\left(y_{\mathrm{g}}^{*} / n\right) \leqslant\left(\frac{n}{n-1}\right) d-\frac{e^{\prime}\left(y_{\mathrm{b}}^{*}\right)}{n-1} .
$$

For part (i), notice that the inequality in Eq. (A.5) always holds for the case of $n=1$. For part (ii), notice that the inequality in Eq. (A.5) fails to hold as $n \rightarrow \infty$, because $c^{\prime}($.) $>d$. It remains only to show that a range of costs exists under which an oligopoly industry produces unit purity under the eco-certification fee (A.4). To see this, define the premium marginal cost locus that meets (A.5) with equality by

$$
\hat{c}^{\prime}\left(y_{\mathrm{g}}^{*} / n\right)=\left(\frac{n}{n-1}\right) d-\frac{e^{\prime}\left(y_{\mathrm{b}}^{*}\right)}{n-1} .
$$

The $\hat{c}^{\prime}\left(y_{\mathrm{g}}^{*} / n\right)$ locus equates with unity when $\hat{d}=\left(n-1+e^{\prime}\left(y_{\mathrm{b}}^{*}\right)\right) / n$. To complete the proof, notice that $\left(d, c^{\prime}().\right)$-pairs exist for which unit purity occurs under oligopoly when $\hat{d}<1$. This implies $e^{\prime}\left(y_{\mathrm{b}}^{*}\right)<1$, which holds by the feasibility condition on brown production, $e^{\prime}\left(y_{\mathrm{b}}^{*}\right)<c^{\prime}\left(y_{\mathrm{g}}^{*} / n\right)$.

Proof of Proposition 4. To obtain the social optimum under monopolistic competition, Eq. (A.4) and inequality (A.5) must be met and $F$ must be selected to reconcile the number of firms in Eq. (17) with the optimal number $\left(n^{*}\right)$ which satisfies Eq. (12). Substitution of $t^{*}=e^{\prime}\left(y_{\mathrm{b}}^{*}\right)$ and $\phi^{*}$ from (A.4) into zero profit condition (17) gives

$$
\left(1+e^{\prime}\left(y_{\mathrm{b}}^{*}\right)-c^{\prime}\left(y_{\mathrm{g}}^{*} / n\right)\right)\left(1+(n-1) c^{\prime}\left(y_{\mathrm{g}}^{*} / n\right)+e^{\prime}\left(y_{\mathrm{b}}^{*}\right)\right)=n^{2}\left(F+c\left(y_{\mathrm{g}}^{*} / n\right)\right) .
$$

At the socially optimal resource allocation, the number of firms must satisfy Eq. (12), or

$$
n c\left(y_{\mathrm{g}}^{*} / n\right)=\left[c^{\prime}\left(y_{\mathrm{g}}^{*} / n\right)-(n-1) c_{\mathrm{b}}\right]\left(1-c^{\prime}\left(y_{\mathrm{g}}^{*} / n\right)+e^{\prime}\left(y_{\mathrm{b}}^{*}\right)\right) .
$$

Eq. (A.7) implicitly defines $n^{*}$. Making use of (A.7) in Eq. (A.6), $n^{*}$ is also the equilibrium number of firms under monopolistic competition when $F^{*}$ is chosen as

$$
F^{*}=\left(1+e^{\prime}\left(y_{\mathrm{b}}^{*}\right)-c^{\prime}\left(y_{\mathrm{g}}^{*} / n\right)\right)\left(1-c^{\prime}\left(y_{\mathrm{g}}^{*} / n\right)+e^{\prime}\left(y_{\mathrm{b}}^{*}\right)+n(n-1) c_{\mathrm{b}}\right) / n^{2} .
$$

The optimal policy pair $\left(\phi^{*}, F^{*}\right)$ in Eqs. (A.4) and (A.8) together with $t^{*}=e^{\prime}\left(y_{\mathrm{b}}^{*}\right)$ reconcile outputs $\left(y_{\mathrm{b}}^{*}, y_{\mathrm{g}}^{*}\right)$ and the number of firms $\left(n^{*}\right)$ with the socially optimal levels in Eqs. (9), (10), and (12). However, this outcome may or may not involve unit purity $\left(\rho^{*}=1\right)$ in the green market. Unit purity occurs only when $y_{\mathrm{b}}^{*}, y_{\mathrm{g}}^{*}$, and $n^{*}$ 
also satisfy inequality (A.5). It is clear by inspection of this boundary that unit purity is an equilibrium outcome whenever

$n^{*}=1$, whereas a range of values of the optimal premium marginal cost, $c^{\prime}\left(y_{\mathrm{g}}^{*} / n^{*}\right)$, exists for which $\rho^{*}<1$ is an equilibrium outcome whenever $n^{*}>1$.

In cases where the policy pair $\left(\phi^{*}, F^{*}\right)$ and the environmental tax rate $t^{*}=e^{\prime}\left(y_{\mathrm{b}}^{*}\right)$ implement the social optimum, certification revenue is given by

$$
\phi^{*} y_{\mathrm{g}}^{*}+n F^{*}=(n-1) c_{\mathrm{b}}\left(1+e^{\prime}\left(y_{\mathrm{b}}^{*}\right)-c^{\prime}\left(y_{\mathrm{g}}^{*} / n\right)\right) / n,
$$

which is positive by condition (3).

Proof of Proposition 5. Under oligopoly, the social optimum involves $\Omega_{\mathrm{g}}=0$ in Eq. (21) and $\Omega_{\mathrm{f}}<0$ in Eq. (20). Eq. (21) is identical to (16), so that the socially optimal output level for the green product occurs through a policy that combines an environmental tax of $t^{*}=e^{\prime}\left(y_{\mathrm{b}}^{*}\right)$ with the unit eco-certification fee given by (A.4). It remains only to show that a monitoring and enforcement policy can be designed to produce a green good that is unit pure. Noting that $\tau^{*}=\phi^{*}-t^{*}$, substitute $t^{*}=e^{\prime}\left(y_{\mathrm{b}}^{*}\right), y_{\mathrm{g}}^{*}=1-c^{\prime}\left(y_{\mathrm{g}}^{*} / n\right)+e^{\prime}\left(y_{\mathrm{b}}^{*}\right)$ and $\phi^{*}$ from (A.4) into (21) to get

$$
\Omega_{\mathrm{f}}=\left((n-1) c^{\prime}\left(y_{\mathrm{g}}^{*} / n\right)+e^{\prime}\left(y_{\mathrm{b}}^{*}\right)\right)(1-\alpha \bar{h}) / n-\alpha \bar{h}\left(c_{\mathrm{b}}+f\right)-d .
$$

Unit purity occurs in equilibrium when $\Omega_{\mathrm{f}}<0$. Clearly, this holds when $\alpha \bar{h}<1$ for sufficiently large levels of $f$. In particular, any monitoring frequency suffices that satisfies

$$
\alpha \bar{h}>\frac{(n-1) c^{\prime}\left(y_{\mathrm{g}}^{*} / n\right)+e^{\prime}\left(y_{\mathrm{b}}^{*}\right)-n d}{(n-1) c^{\prime}\left(y_{\mathrm{g}}^{*} / n\right)+e^{\prime}\left(y_{\mathrm{b}}^{*}\right)+n\left(c_{\mathrm{b}}+f\right)} .
$$

To complete the proof of feasibility under oligopoly, notice that the right-hand side of (A.9) is strictly less than unit value when $f=0$.

Under monopolistic competition, Proposition 5 establishes that the optimal policy pair $\left(t^{*}, \phi^{*}, F^{*}\right)$ in Eqs. (A.4) and (A.8) reconcile outputs $\left(y_{\mathrm{b}}^{*}, y_{\mathrm{g}}^{*}\right)$ and the number of firms $\left(n^{*}\right)$ with the socially optimal levels in Eqs. (9), (10), and (12). A monitoring frequency which satisfies (A.9) guarantees that $\Omega_{\mathrm{f}}<0$ for $n^{*}$; hence unit purity is obtained.

Proof of Proposition 6. Under endogenous detection, $\gamma_{\mathrm{f}}(1)=\gamma_{\mathrm{g}}(1)=0$ at a unit purity level. Hence, (18) and (19) are identical to (15) and (16) at a unit purity level.

\section{References}

[1] G. Amacher, E. Koskela, M. Ollikainen, Environmental quality competition and eco-labeling, J. Environ. Econ. Manage. 47 (2004) 284-306.

[2] R. Bénabou, R. Gertner, Search with learning from prices: does increased inflationary uncertainty lead to higher markups?, Rev. Econ. Stud. 60 (1993) 69-94.

[3] P. Callahan, P.S. Kilman, Laboratory tests belie promises of some 'GMO-Free' food labels, The Wall Street Journal, April 5, 2001.

[4] Consumer Reports, Organic produce 63 (1998) 12-18.

[5] C. Crampes, A. Hollander, Duopoly and quality standards, Eur. Econ. Rev. 39 (1995) 71-82.

[6] M. Darby, E. Karni, Free competition and the optimal amount of fraud, J. Law Econ. 16 (1973) 67-88.

[7] R. Denn, Food labels don't always stick to the rules: some foods deemed eco-friendly may not be, Seattle Post-Intelligencer Reporter, November 26, 2003.

[8] J. Doward, M. Townsend, A. Wander, Britain's organic food scam exposed, The Observer, August 21, 2005.

[9] S. Engel, Achieving environmental goals in a world of trade and hidden action: the role of trade policies and eco-labeling, J. Environ. Econ. Manage. 48 (2004) 1122-1145.

[10] M. Groves, Firm enters plea in false labeling case, Los Angeles Times, May 15, 1998.

[11] S. Hamilton, D. Sunding, D. Zilberman, Public goods and the value of product quality regulations: the case of food safety, J. Public Econ. 87 (2003) 799-817. 
[12] A. Malik, Further results on permit markets with market power and cheating, J. Environ. Econ. Manage. 44 (2002) $371-390$.

[13] Marketing Intelligence Service, ProductScan Online, Marketing Intelligence Service Ltd., New York, 1999.

[14] K. Mergentime, Organic fraud case deepens: possible link causes OCIA turmoil. The Natural Foods Merchandiser, XVIII (1997) 7-10.

[15] M. Meyer, J. Vickers, Performance comparisons and dynamic incentives, J. Polit. Econ. 105 (1997) $547-581$.

[16] M. Mussa, S. Rosen, Monopoly and product quality, J. Econ. Theory 23 (1978) 301-317.

[17] W. Novshek, On the existence of Cournot equilibrium, Rev. Econ. Stud. 52 (1985) 85-98.

[18] OECD, Eco-labeling: Actual Effects of Selected Programs, Organization for Economic Co-operation and Development, GD 97, 1997.

[19] W. Rogerson, Reputation and product quality, Bell J. Econ. 14 (1983) 391-401.

[20] U. Ronnen, Minimum quality standards, fixed costs and competition, RAND J Econ 22 (1991) 490-504.

[21] P. Rzewnicki, Ohio organic producers: Final survey results, Ohio State University Special Circular 174-00, 2000 <http:// ohioline.osu.edu/sc174/sc174_2.html >.

[22] D. Smallwood, J. Conlisk, Product quality in markets where consumers are imperfectly informed, Quart. J. Econ. 94 (1979) 1-23.

[23] G. Smith, Ordinary grain sold as organic in $3 \mathrm{~m}$ fraud. The Evening Standard, June 11, 2001.

[24] A. Starks, Certified naturally grown: a different kind of organic. The Satya interview with Ron Khosla. Satya, December $2005<$ http://www.satyamag.com/dec05/khosla.html $\rangle$.

[25] S. Swallow, R. Sedjo, Eco-labeling consequences in general equilibrium: a graphical assessment, Land Econ 76 (2000) $15-27$.

[26] J. Tirole, A theory of collective reputations (with applications to the persistence of corruption and to firm quality), Rev. Econ. Stud. 63 (1996) 1-22.

[27] US Environmental Protection Agency, Status Report on the Use of Environmental Labels Worldwide, Washington DC, 1993. 